\title{
Influence of AM fungi inoculation on Capsicum annuum L. plant grown in microwave-sterilized media
}

\author{
Aulia Brellian Pratama ${ }^{1}$, Wibowo Mangunwardoyo ${ }^{1}$, Nicholas Dwi Chandra ${ }^{1}$, Toga \\ Pangihotan Napitupulu ${ }^{2}$, Idris Idris $^{2}$, Atit $\mathrm{Kanti}^{2}$, Azra Zahrah Nadirah Ikhwani ${ }^{2}$, I Made \\ Sudiana $^{2}$, and Ikhsan Guswenrivo ${ }^{3 *}$ \\ ${ }^{1}$ Department of Biology, Faculty of Mathematics and Natural Sciences, University of Indonesia, \\ Margonda Raya Street, Depok, West Jawa, Indonesia, 16424 \\ ${ }^{2}$ Research Center for Biology. Indonesian Institute of Science (LIPI) Cibinong. Raya Bogor Street \\ Km. 46, Cibinong, Bogor, West Jawa, Indonesia 16911 \\ ${ }^{3}$ Research Center for Biomaterial Indonesian Institute of Science (LIPI) Cibinong. Raya Bogor Street \\ Km. 46, Cibinong, Bogor, West Jawa, Indonesia 16911
}

\begin{abstract}
The presence of arbuscular mycorrhizal in soil may affect growth and yield of chili (Capsicum annuum L.). This experiment was done to know the effect of arbuscular mycorrhizal inoculation on growth of chilli. Microwave soil sterilization was used to reduce the number of microbes in the media, enabling to observe the interaction between chili peppers and arbuscular mycorrhizal fungi. A single culture products (A) and mixed culture products (B) were used as arbuscular mycorrhizal spores. In contrast to product $\mathrm{A}$, the spore counted calculation reported that product B had the most spores, with 51 spores / $50 \mathrm{~g}$ soil. The treatment of arbuscular mycorrhizal fungi and microwave sterilization against the height of chili plant had no significant effect, according to a two-factor ANOVA ( $\alpha$ : 0.05) analysis of agronomic characteristics. Inoculation of mycorrhizae had a significant effect on chili plant height. Arbuscular mycorrhizal fungi inoculation and microwave sterilization had significant effect on the root length of chili plants. Arbuscular mycorrhizal fungi in single and mixed cultures could colonize roots by forming internal hyphae, vesicles, and spores. The best way to support the growth of chili plants is to use planting media that has not been sterilized and contains mycorrhizal fungi.
\end{abstract}

\section{Introduction}

Chili cultivation often cause national inflation in Indonesia. This occurs due to the increasing demand of chili over time. Chili is considered valuable because of its role as food additive in many Indonesian cuisines. One of the agricultures that influences national inflation is chili agriculture (Capsicum annuum L.). For Indonesians, the chili produced serves as a valuable food component. Chili plants should be developed in order for them to

* Corresponding author: ikhsan.guswenrivo@biomaterial.lipi.go.id 
help the community's well-being. Red and green chilies, large red chilies, and curly chilies are among the many varieties of chili available [1]. Chili commodities, are in more demand every year. Red and green chilies had a 14 percent increase in demand between 2006 and 2014, while cayenne chilies had a 21 percent increase. On the other hand, Chili cultivation has several challenges, including lower harvest prices, pathogen and pest attacks, heavy rains, and natural disasters [2]. Some of these factors have a significant effect on national inflation in the chili agricultural sector.

Chili (Capsicum annum L.) is a plant belonging to the Solanaceae family, consisting of 36 species. Chili has a high diversity in shape, size, flavor, color, scent, and spiciness. Because chili plants are rich in vitamin A and vitamin $\mathrm{C}$, these can be utilized as a health element. Chili plants are shown to associate with microbes to increase their growth and development, mainly associating with arbuscular mycorrhizal fungi (AMF). Chili plant interactions with the arbuscular mycorrhizal fungus can increase the sustainability of chili plants in various situations, especially low-nutrient soil [3].

Mycorrhizal fungi are fungi in the soil which develop a non-pathogenic symbiosis with plant roots. Some Gymnospermeae such as Pteridopita, lycopodia, mosses, and the Angiospermeae are all host plants for mycorrhizal fungi [4]. Glomus, Gigaspora, Scutellospora, and Acaulospora are the most commonly observed arbuscular mycorrhizal fungi interacting with chili plants. Arbuscular mycorrhizal fungi may improve plant mineral and nutrient absorption, soil and water interactions, plant tolerance or resistance to adverse conditions, and soil structure. Arbuscular mycorrhizal fungi get their nutrients from the carbon metabolism of the plants [3].

Chili farming must be developed in order to improve the economy in Indonesia. One approach to improve chili production besides adding fertilizer is by introducing arbuscular mycorrhizal fungus propagules to improve plant growth efficiency [5]. Sterilized planting media is a solution to seeing the interaction between arbuscular mycorrhizae and chili plants. However, there is currently no study on the impact of planting media sterilization methods injected with arbuscular mycorrhizal fungal propagules on chili plant growth. As a result, research on the impact of arbuscular mycorrhizal fungi on the development of chili (Capsicum annuum L.) in growing media with microwave sterilization methods is needed. It is predicted that the effect of sterilization of planting media on the growth of chili plants in the nursery phase and the interaction between arbuscular mycorrhizal fungi in supporting the development of chili plants may be observed through this research.

\section{Materials and methods}

The research was conducted at LIPI Cibinong, West Java, from July to September 2020. The research was conducted out using a two-factor randomized block design (RBD). The first factor was its sterilization method of chili growing media, microwave sterilization, and without sterilization.. The treatment of arbuscular mycorrhizal fungus with a single culture of Glomus mosseae and a mixed culture was the second factor. The treatment setting was replicated ten times, producing a total of 40 experiment units. The results obtained were analyzed using two-factor ANOVA and tested with SPSS software. The experiment was carried in a greenhouse. The chili seeds were planted in a media tray.

\subsection{Sterilization and soaking the seeds}

In a $100 \mathrm{~mL}$ Erlenmeyer flask, place the seeds of the chili plants. The seeds were sterilized for 8 minutes in a 0.05 percent hypochlorite solution. Seeds of lower quality will float to the surface after sterilization, whereas good-quality seeds will fall to the bottom of the hypochlorite solution. The scent of the hypochlorite solution is removed by washing out of 
good quality chili seeds several times utilizing sterile distilled water. After washing, the seeds are soaked for 24 hours in a petri dish containing sterile distilled water.

\subsection{Planting media sterilization and production}

Microwave-sterilized compost planting medium was produced by heating it for 2.5 minutes at a maximum temperature of $250^{\circ} \mathrm{C}$ [6]. A digital scale was used to weigh the compost planting medium, which was up to $30 \mathrm{~g}$. The planting media is placed in the tray hole after it has been weighed.

\subsection{Sowing seeds and providing propagules}

A zeolite bio carrier containing arbuscular mycorrhizal fungus propagules is placed in the tray containing up to $10 \mathrm{~g}$ of planting medium. For mycorrhizal bio carrier A, up to $10 \mathrm{~g}$ of zeolite bio carrier was placed into the tray hole, while mycorrhizal bio carrier B got only 5 g. The chili seeds are placed on top of the zeolite bio carrier layer after the zeolite bio carrier layer has been added, and then covered again with $10 \mathrm{~g}$ of the previously taken planting medium. A total of $40 \mathrm{~g}$ of zeolite and mycorrhizal fungi propagules was used in the research.

\subsection{Watering and fertilizing plants}

For six weeks, use a plant sprayer to moist the seeds in the tray with tap water. The chili plants are watered by circling their stems. Watering was applied at 09.00-10.00 in the morning and 16.00-17.00 in the evening. Hoagland's solution is composed of two parts: a macronutrient solution and a micronutrient solution. For one month, fertilization is repeated once a week. Each hole was sprayed with Hoagland solution, which was then applied to all of the seeds.

\subsection{Plant agronomic parameters observation}

A ruler to measure the height of the plants from the base of the stem to the highest point. The plant's height was measured for six weeks. The morphology and development characteristics of the roots were studied to determine plant root architecture. The roots of the chili plants were washed with clean water. The length of the plant roots and the architecture of the plant roots were observed when chili is already harvested.

\subsection{Root colonization observation}

The root sample was washed, cut, and placed in the test tube. The chili root pieces are then placed in a test tube containing a $10 \% \mathrm{KOH}$ solution, heated for 15 minutes at $60^{\circ} \mathrm{C}$ in a water bath filled with water. After removing the $\mathrm{KOH}$ solution, the chili root pieces were washed with distilled water. For 1 minute, soak chiles in a $2 \% \mathrm{HCl}$ solution. The $\mathrm{HCl}$ solution was then discarded, and the root pieces were rinsed with distilled water. For 24 hours, root pieces were soaked in Trypan Blue dye reagent. Root pieces stained with Trypan Blue, soaked in $2 \mathrm{~mL} 50$ percent glycerol solution, then observed under a light microscope [7]. 


\subsection{Quantification of spore populations}

The spore quantification was used before the treatment on the chili plants began. A beaker containing $400 \mathrm{~mL}$ of distilled water is mixed with $50 \mathrm{~g}$ of soil. After 15 minutes of stirring, the water is filtered through a $75 \mu \mathrm{m}$ filter through a $54 \mu \mathrm{m}$ filter. $100 \mathrm{~mL}$ of distilled water was used to extract the spores from the filter. After the spores have accommodated, $65-70 \%$ of the entire amount of distilled water is mixed with sugar, then homogenized. The sugar solution-coated homogenous spores were put on a Petri plate and observed under a stereomicroscope.

\section{Results and Discussions}

\subsection{Arbuscular mycorrhizal fungi spores on carrier products population}

Table 1 shows the results of quantifying the arbuscular mycorrhizal spore population on the two carrier products used in this study. Analyses and observations showed that carrier product B contained 51 spores / $50 \mathrm{~g}$ soil.

Tabel. 1. Results of the arbuscular mycorrhizal spore count

\begin{tabular}{|c|c|c|}
\hline $\begin{array}{c}\text { Carrier } \\
\text { product }\end{array}$ & $\begin{array}{c}\text { Total of spore } \\
\text { (spore / 50 g) }\end{array}$ & Spore \\
\hline $\begin{array}{c}\text { A (single } \\
\text { culture) }\end{array}$ & 39 & Glomus mosseae \\
\hline $\begin{array}{c}\text { B (mixed } \\
\text { culture) }\end{array}$ & 51 & $\begin{array}{c}\text { Acaulospora } \text { sp., Gigaspora sp., Glomus } \\
\text { mosseae, and Scutellospora } \text { sp. }\end{array}$ \\
\hline
\end{tabular}

The morphology of arbuscular mycorrhizal fungus spores show that the genera Acaulospora, Glomus, and Gigaspora dominate the mixed culture carrier products. The three genera of arbuscular mycorrhizae enhance growth, particularly in chili plants (Capsicum annuum L.). These genera of arbuscular mycorrhizae can be discovered throughout the rhizosphere of chili plants [3]. The carrier product contained four genera of arbuscular mycorrhizae, namely Glomus, Acaulospora, Gigaspora, and Scutellospora (Fig. 1). Subglobose, globose, obovoid, and ovoid spore morphologies are found in the Glomus genus. Glomus spore walls are multilayered, varying from yellowish-white to yellow, brownish red, and black. The spores of the Acaulospora genus range in size from elliptical to globose. Acaulospora spores are bone white, yellowish, or yellowish red and have 2-3 spore walls. Subglobose or globose spores are found in the genus Gigaspora. The spores of the genus Gigaspora were cream to yellowish and without any spore wall layer. Obovoid, ovoid, irregular, and pyriform spores are all found in the Scutellospora genus. The germination shield on Scutellospora spores differs from that on Gigaspora spores [8]. 


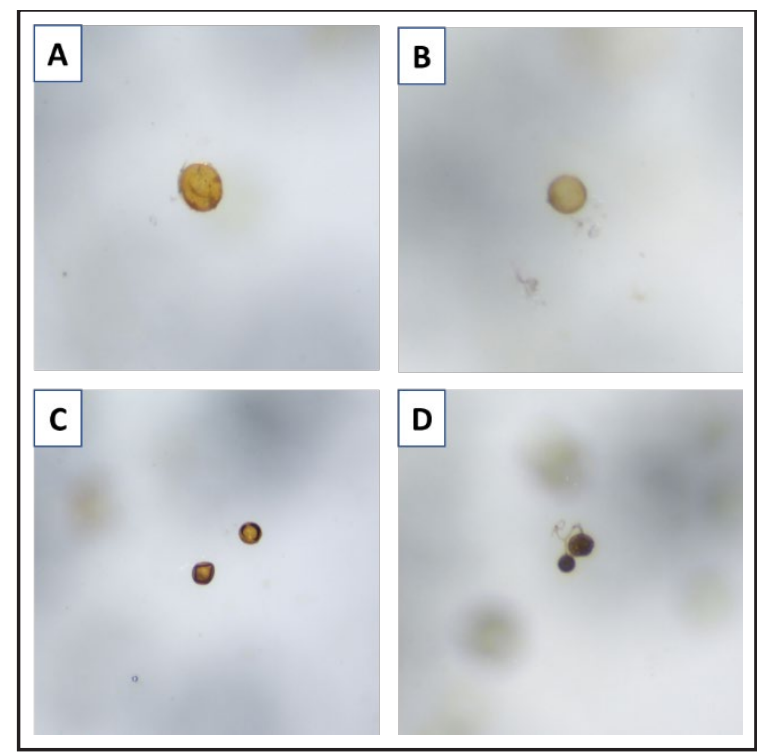

Fig. 1. The morphologies of arbuscular mycorrhizae fungi in bio carrier. A: Scutellospora sp.; B: Gigaspora sp.; C: Acaulospora sp.; D: Glomus sp.

\subsection{Agronomy of chili plants}

Plant height under different mycorrhizal inoculation and media sterilization was presented in Figure 2. Based on a two-factor ANOVA $(\alpha: 0.05)$ test, there were no interaction effect of the two factors on plant height, however the two treatments had different effect on plant height. The significance value for the interaction of arbuscular mycorrhizae and growing media sterilization method was $0.268(\mathrm{p}>\alpha)$. Media sterilization has no significant effect on plant height. The treatment of arbuscular mycorrhizal carrier products, on the other hand, had a significant effect on the average height of chili plants $(\mathrm{p}=0)$. Figure 2 showing that chili plants using mycorrhizal fungi $\mathrm{B}$ had a higher result than chili plants using mycorrhizal fungi A.

The average height of chili plants

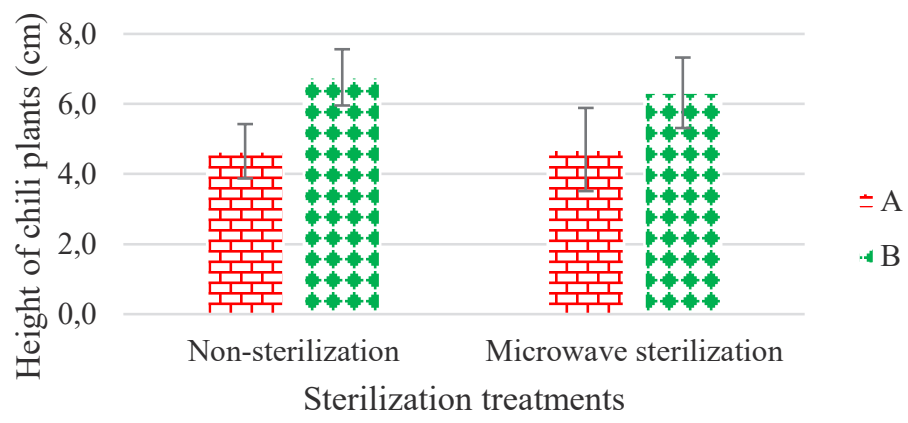

Sterlization (ns); AMF (*); sterilization $\times$ AMF (ns)

Fig. 2. Chili (Capsicum annuum L.) plant height average over treatments. Values are means $\pm \operatorname{SE}(n=$ 3), Two-way ANOVA output: ns, not significant;* $\mathrm{p}<0,05$.

The use of compost without sterilization can produce an improved result for most carrier products that are used, even though it has no significant effect. Because it works as a 
consortium of various microorganisms, Figure 2 shows that the compost growing media without sterilization is relatively supportive of chili plant growth. Microwave sterilization of planting media could remove certain microorganisms in the top layer of soil, decreasing microorganism-plant interaction [9]. Furthermore, toxic compounds such as phenol and 5hydroxymethyl-2-furaldehyde can be produced from compost or soil when sterilized media are used, which can inhibit plant growth $[6,10]$.

The average root length of the chili (Capsicum annuum L.) differs based on the treatment. In compost growing media without sterilization and microwave sterilization, treatment of mixed culture mycorrhizal fungi product B had the best yield on average root length of chili plants, according to Figure 3. The more mycorrhizal fungus colonization in the roots, the more potential chili plants' roots would grow longer. Plant roots were observed to be longer on growing media that had not been sterilized and used mixed culture mycorrhizal products. However, the two-factor ANOVA statistical test results showed no significant difference in root length between sterilization and mycorrhizal treatments in chili plants.

The average root length of chili plants

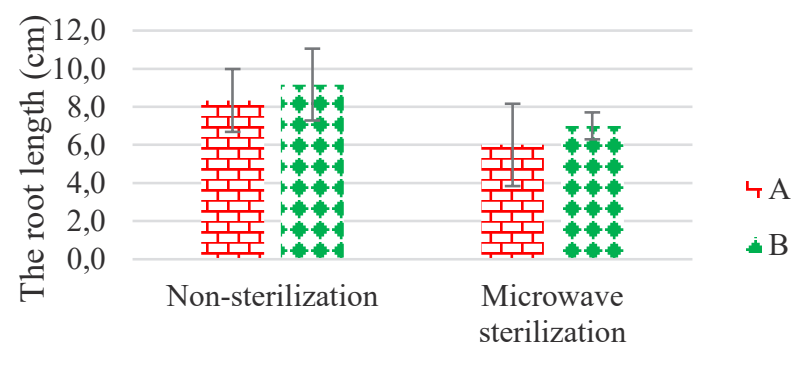

Sterilization treatments

Sterlization (ns); AMF (ns); sterilization $\times$ AMF (ns)

Fig. 3. The average root length of chili plants. Values are means $\pm \mathrm{SE}(n=3)$, Two-way ANOVA output: ns, not significant; ${ }^{\mathrm{p}}<0,05$.

Compared to the length of roots in planting media with microwave sterilization, the roots of chili plants on non-sterile growth media tend to be longer. The compost sterilization method could produce toxins [11]. Besides arbuscular mycorrhizae, other living organisms, mainly bacteria, promote plant growth in non-sterile compost growing media. According to previous research, bacteria have a role in hyphae growth and arbuscular mycorrhizal fungi's mycorrhizal ability on host plants $[11,12]$. There are bacteria and fungi in compost that can stimulate growth directly and increase plant growth through various mechanisms, including phosphate dissolution and the production of plant growth hormones such as auxins [13,14,15].

Figure 4 shows the root architecture of chili plants (Capsicum annuum L.). According to observations, the architecture of the roots of chili plants showed that the plants' roots were taproots according to observations. Taproots can generate secondary roots to increase nutrient absorption from the environment. 


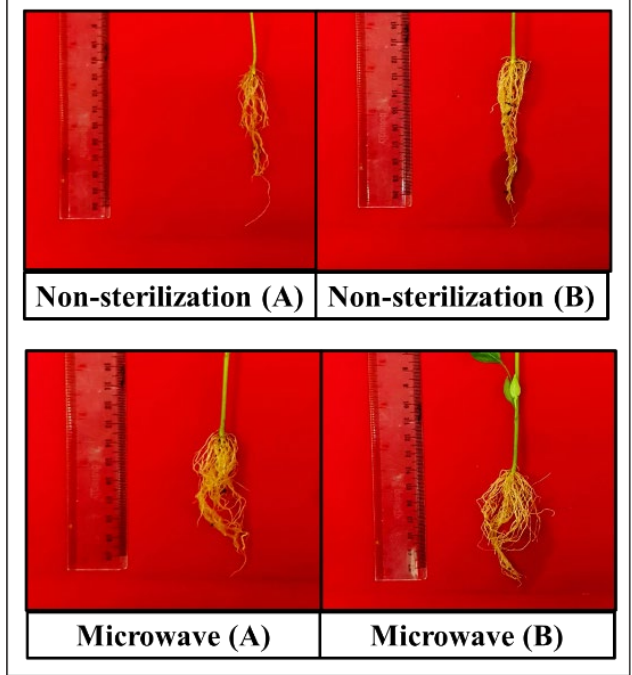

Fig. 4. The architecture root of chili plants in various treatments

External hyphae are likely to appear on secondary roots to help plants absorb nutrients, [16]. The results showed no significant difference in root density between chili plants grown in non-sterile compost growing media and those grown in sterile compost growing media after microwave sterilization. When compared plants inoculated with mycorrhizal fungi product $\mathrm{B}$ to plants inoculated with mycorrhizal fungi product $\mathrm{A}$ in various treatments, the root density of chili plants inoculated with product B was tremendous, the colonization of mycorrhizal fungi in association with chili plants will be most quick to attribute.

\subsection{The arbuscular mycorrhizal fungi colonization in chili plant roots}

Observations of arbuscular mycorrhizal infections in chili plants (Capsicum annuum L.) using the sterilization technique showed that all treatments resulted in plant root infection. Arbuscular mycorrhizae discovered in the roots and around chili plants had spores, vesicles, and internal hyphae formed from single and mixed culture products, according to Figure 5. Other than arbuscular mycorrhizal fungi produced from carrier products, the sterilization method aims to eliminate the diversity of microorganisms.
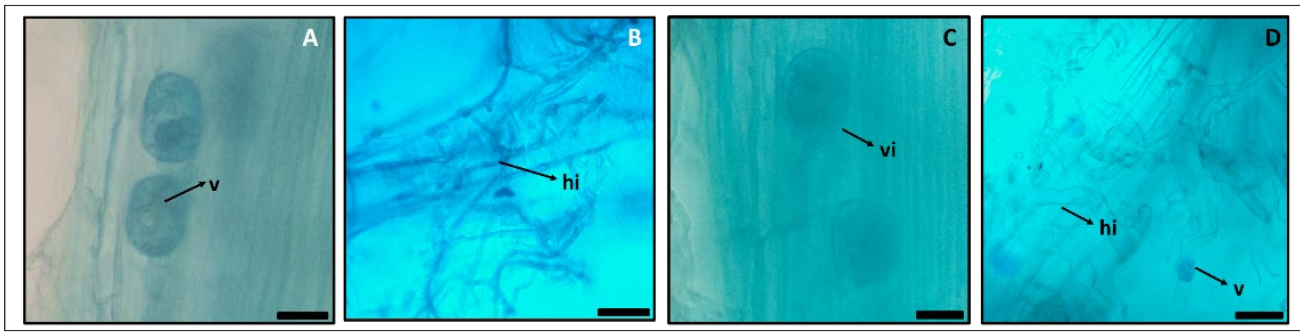

Fig. 5. The colonization in root chili plant. A: Carrier product $A$ in non-sterlization method soil (v: vesicle). B: Carrier product B in non-sterlization method soil (hi: internal hyphae). C: Carrier product A in microwave sterilization method soil (v: vesicle). D: Carrier product B in microwave sterilization method soil (v: vesicle; hi: iternal hyphae). Scale bar A,B, and C: $20 \mu \mathrm{m}$; scale bar D: $50 \mu \mathrm{m}$. 
The sterilization method can decrease the density of mycorrhizal spores in the plant rhizosphere by lowering the number of microorganisms in the growing media [7]. As a consequence, the compost sterilization method did not affect arbuscular mycorrhizal infection in chili plants. Nutrients, environmental conditions, and the compatibility of the host plant and inoculum are all factors that influence arbuscular mycorrhizal infection in plants. The possibility of arbuscular mycorrhizal infection with chili plants due to environmental factors such as dry environmental conditions were observed during the observation.

\section{Conclusions}

Our findings showed that mixed culture arbuscular mycorrhizal fungi products supported the growth of chili plants more than single culture products in length of root and plant height. The sterilization of growing media, on the other hand, had a minor effect on the growth of chili plants in the nursery phase. The interaction of arbuscular mycorrhizal fungi with plants revealed no significant effect on improving chili plant growth. In conclusion, the microwave sterilization method had no significant results, whereas the use of AMF to chili plants could have a significant effect on the development.

\section{References}

1. A.R. Yanuarti, M.D. Afsari, Profil komoditas barang kebutuhan pokok dan barang penting: Komoditas cabai (2016)

2. M.J. Anwarudin, A.L. Sayekti, A. Marendra, Y. Hilman, Pengemb. Inov. Pertan. 8, 33 (2015)

3. J.A.P. Pereira, I.J.C. Vieira, M.S.M. Freitas, C.L. Prins, M.A. Martins, R. Rodrigues, J. Agric. Sci. 154 (2015)

4. D. Strack, T. Fester, B. Hause, W. Schliemann, J. Chem. Ecol. 29 (2003)

5. Musfal, JPPP. 29 (2010)

6. G. Brodie, M.J. Khan, D. Gupta, Microwave soil treatment and plant growth, in Book of the Crop production (2019)

7. A.D. Nusantara, Y.H. Bertham, I. Mansur, Bekerja dengan fungi mikoriza arbuskula (2012)

8. M.E.E. Miska, A. Junaedi, A. Wachjar, I. Mansur, JST. 7, 18 (2016)

9. W.T. Runia, L.P.G. Molendijk, Acta Hortic. 883 (2010)

10. J.C. Cardoso, A.C.P. Imthurn, J. Ornam. Hortic. 24 (2018)

11. V. Artursson, R. D. Finlay, J.K. Jansson, Environ. Microbiol. 8,1(2006)

12. A. Nanjundappa, D.J. Bagyaraj, A.K. Saxena, M. Kumar, H. Chakdar, Fungal Biol Biotechnol. 6 (2019)

13. O. Dai, R.K. Singh, G. Nimasow, Afr. J. Microbiol. Res. 5 (2011)

14. M. Datta, R. Palit, C. Sengupta, M.K. Pandit, S. Banerjee, Aust. J. Crop Sci. 5, 531 (2011)

15. A. Sugiharto, T.P. Napitupulu, I.M. Sudiana, JMSB. 2 (2020)

16. I. Arifin, Pengaruh cara dan lama penyimpanan terhadap mutu cabai rawit (Capsicum fructesens L. var. Cengek) (Thesis Faculty of Sciences and Technology Universitas Islam Negeri Maulana Malik Ibrahim, Malang, Indonesia 2010) 